\title{
自然资源综合调查业务体系框架
}

\author{
葛良胜, 夏 锐 \\ (中国地质调查局自然资源综合调查指挥中心, 北京 100055)
}

\begin{abstract}
摘要：以习近平新时代生态文明建设思想和“山水林田湖草是一个生命共同体”理念为指导, 从自然资源概念、内涵和属性分析人手, 提出服务于综合调查业务的自然资源立体分层分类方 案, 确定陆域自然资源主要包括地下空间、矿产、浅表地质层、土地、水、森林、草和湿地等 8 个基 本类, 并建立其时空和属性结构模型。以此为基础, 初步构建以统一(基础)调查、专项专题调 查、动态监测与数据更新、数据处理与综合集成、成果表达与应用服务为基本流程的自然资源 综合调查业务体系框架, 并对各阶段业务工作内容和要求进行了概略讨论, 以期为自然资源综 合调查业务体系重构提供参考。
\end{abstract}

关键词：自然资源;分类;时空属性结构;综合调查;业务体系框架

自然资源是可为人类使用，客观存在于宇宙空间内自然环境要素的总和。地球系统 是为人类提供自然资源最重要的载体。随着地球上人口及其生存和生活需求的增长，人 类消费、利用自然资源欲望的扩张和膨胀，以及人们对自然资源管理混乱、野蛮占有、 无序开发等，引发了大量的资源环境和生态问题 ${ }^{[1-8]}$ 。在技术层面，自然资源分类不够科 学，体系不够完整；对不同类型自然资源之间的相互关系和互馈机制、资源开发利用与 生态环境保护相互影响的基本表现和内存规律等认识不够深人 ${ }^{[9-13]}$ 。延伸到管理层面, 由 于不同类型自然资源分属不同部门管理，出现了权属边界不清晰、空间交叉重叠多、数 据标准不统一、成果集成应用难等现实问题。习近平 ${ }^{[4]}$ 从生态文明建设和全球治理的高 度，针对自然资源管理、开发与利用等，提出了 “山水林田湖草是生命共同体”与 “人 与自然和谐共生” 等理念。同时自然资源部的成立标志着自然资源管理业务及相关职能 的重构, 为自然资源综合调查监测等工作提出了更高的要求和标准 ${ }^{[15,16]}$ 。基于自然资源的 自然属性、经济社会属性和生态属性, 为满足自然资源综合管理和合理开发利用要求, 构建和完善自然资源综合调查监测业务体系架构, 科学部署自然资源综合调查工作已成 为当务之急 ${ }^{[10]}$ 。本文基于前人相关研究 ${ }^{[1-3,6]}$, 从自然资源基本概念、特征属性人手, 通过 阐明自然资源类型及其时空一属性结构，深化认识不同类型自然资源相互关系和内在规 律, 结合自然资源统一管理的基本要求，构建了自然资源综合调查业务体系框架，旨在 为组织和部署开展自然资源综合调查相关工作提供借鉴，为统筹推进自然资源管理制度 和体制改革提供参考。

\footnotetext{
收稿日期：2019-10-13；修订日期：2020-02-11

基金项目：自然资源部2019年度全国森林蓄积量调查（DD20208031）；中国地质调查局自然资源综合调查计划 (DD2020013)
}

作者简介: 葛良胜 (1966-), 男, 安徽潜山人, 博士, 研究员/高级工程师, 博士生导师, 主要从事自然资源科学研 究和管理工作。E-mail: geliangsheng@aliyun.com 


\section{1 自然资源概述}

\section{1 基本概念}

人类认识和利用自然资源的历史久远，自然资源范畴也随着人类社会和科学技术的 发展而不断拓展 ${ }^{[1]}$ 。表 1 列举了不同领域学者对自然资源概念的定义与描述。可以看出, 自然资源概念涵盖内容十分广泛, 涉及地球科学、经济学、生态学和社会学等不同学 科领域 ${ }^{[17]}$ 。

\section{表 1 自然资源科学定义及其内涵}

Table 1 Scientific definition and connotation of natural resources

\begin{tabular}{|c|c|}
\hline 来源 & 自然资源定义及内涵 \\
\hline Zimmermann $^{[18]}$ & $\begin{array}{l}\text { 只有自然环境或其某些部分能够满足人类需要才叫自然资源; 不能被人类获取利用的只 } \\
\text { 是叫自然禀赋（环境禀赋） }\end{array}$ \\
\hline 联合国环境规划署 ${ }^{[19]}$ & $\begin{array}{l}\text { 人在自然环境中发现的各种成分, 只要它能以任何方式为人类提供福利, 都属于自然资 } \\
\text { 源; 在一定时间条件下, 能够产生经济价值以提高人类当前和未来福利的自然环境因素 } \\
\text { 的总称 }\end{array}$ \\
\hline 辞海编辑委员会 ${ }^{[20]}$ & $\begin{array}{l}\text { 一般指天然存在的自然物 (不包括人类加工制造的原料), 是生产的原料和布局场所, 如 } \\
\text { 土地、矿藏、水利、生物、海洋等 }\end{array}$ \\
\hline 李文华等 ${ }^{[2]]}$ & $\begin{array}{l}\text { 指存在于自然界中能被人类利用或在一定技术、经济和社会条件下能被用作生产、生活 } \\
\text { 的物质、能量的来源, 或在现有生产力发展水平和研究条件下, 为满足人类生产、生活 } \\
\text { 需要而被利用的自然物质和能量 }\end{array}$ \\
\hline 孙鸿烈 ${ }^{[22]}$ & 人类可以利用的、自然生成的物质与能量 \\
\hline 封志明 ${ }^{[23]}$ & $\begin{array}{l}\text { 一定社会经济技术条件下, 能产生生态价值或经济效益, 以提高人类当前或可预见未来 } \\
\text { 生存质量的自然物质和自然能量的总和 }\end{array}$ \\
\hline 万年庆等 ${ }^{[1]}$ & 指在一定时间条件下，具有某种功能以提高人类当前和未来福利的自然环境因素的总称 \\
\hline 李文华 ${ }^{[3]}$ & $\begin{array}{l}\text { 自然界天然存在的、可以为人类利用的物质与能量的总称, 是人类生存的物质基础和社 } \\
\text { 会发展的动力源泉 }\end{array}$ \\
\hline 蔡运龙 & $\begin{array}{l}\text { 人类能够从自然界获取以满足其需要与欲望的任何天然生成物及作用于其上的人类活动 } \\
\text { 结果; 自然资源是人类社会取自自然界的初始投人 }\end{array}$ \\
\hline 自然资源部 ${ }^{[25]}$ & 指天然存在、有使用价值、可提高人类当前和未来福利的自然环境因素的总和 \\
\hline
\end{tabular}

本文认为，自然资源有广义和狭义之分。广义上，自然资源应包括宇宙空间内所有 可为人类利用的自然环境要素，主要指依附于时间和空间而存在的物质和能量，甚至时 间和空间本身也可以看成是自然资源的组成部分。狭义上，自然资源主要指客观存在于 地球系统中并能为人类利用的空间、物质和能量等自然环境要素及其组合。与表 1 所列 主要观点相比，这里特别强调了某些空间资源（如地下空间）和组合资源（如湿地等）。 作为自然资源统一管理和调查监测的对象，人们更加注重那些看得见、摸得着，可以实 施调查、监测和控制的自然资源实体，即主要以物质形式存在的自然资源要素。本文拟 构建的自然资源综合调查业务体系架构，其指向主要是狭义层次上的自然资源。

\section{2 基本属性特征}

以有限空间或物质实体形式存在的自然资源，具有自然、经济、社会、生态等多重 基本属性特征 ${ }^{[26,27]}$ 。

（1）自然属性。包括时间、空间、质量和关联等。时间属性，即资源实体会在不同 时间尺度上表现出或快或慢、这样或那样的变化。因此，自然资源的调查应确定基本时 间点和限定时间点，并明确调查周期。正因为它会随时间发生变化，对变化的监测就成 
为可能且非常必要。空间属性, 即资源实体会占据一定的空间位置和范围, 具有一定的 外观和形状，如位置坐标、长宽高、面积、体积等，它们是自然资源调查和监测定量描 述的基础。质量属性，作为物质形式存在的自然资源，必然有其质和量的描述，而不同 类型的资源描述其质和量的指标也会明显不同。在调查和监测中，应根据各类自然资源 的特点, 按照统一性和特色性相结合的原则, 分别确定相应的质量指标体系。关联属 性，指不同类型自然资源之间是相互联系和相互制约的，当其中一种发生变化时，会诱 发或引起其他关联性变化或连锁反应, 这是 “山水林田湖草是生命共同体” 理念的直接 表现 ${ }^{[28]}$ 。正是这种关联性存在，才使得统一组织管理、统一调查监测、统一规范标准、 统一整理集成等成为必要。

（2）经济属性。包括有效（用）性、有限性、稀缺性和区域性等。自然资源之所以 是资源, 是因为其具有经济属性。自然资源的价值按其对人类需要的可满足程度有大小 之分。通常情况下，越难以满足人类需要的资源其价值越大，且随着时间、状态、形势 变化而变化。不同类型自然资源本质特点和相互之间的关联性决定其时空分布的不均匀 性及其秉赋特征。自然资源的时空不均匀性和其秉赋条件是对其实施调查时需要重点掌 握的内容。

（3）社会属性。人类在开发、使用自然资源过程中会融人社会劳动，而这种社会劳 动又会对自然资源的本底特征和自然属性施加影响, 从而改变其时空结构和质量状态, 是其社会属性的具体反映。

（4）生态属性。自然资源生态属性表现为其所具有的环境功能。生态是生物（包括 人）生存、生产、生活状态及其与环境相互关系的总和，而环境又是生物周围空间一切 影响生物存在状态各自然要素的总称 ${ }^{[29]}$ 。正是不同尺度上的自然资源生态过程最终综合 决定了相关地区的生态状况，因此，不能脱离自然资源去研究生态问题。自然资源综合 调查监测工作是有效实施生态环境保护、修复等的前提和基础。

\section{2 分类及时空属性结构}

\section{1 分类方案}

尽管人类一直在寻找、开发、利用、消费和研究各种各样的自然资源，但迄今对自 然资源分类没有形成统一意见 ${ }^{[24]}$, 多案并存和交叉重叠问题突出 ${ }^{[11,12,30]}$ 。有学者基于自然 资源经济属性研究, 将其分为耗竭性资源和非耗竭性资源, 这与 Haggett ${ }^{[3] 1}$ 的不可更新资 源和可更新资源（又进一步分为恒定性资源和临界性资源）的分类相似；还有人根据用 途将其划分为农业资源、工业资源、服务业资源（交通、医疗、旅游、科技等）等。根 据自然资源空间属性，有学者将其分为矿产资源（地壳）、气候资源（大气圈）、水力资 源（水圈）、土地资源（地表）、生物资源（生物圈）五类，各类还可以进一步细分，这 一分类有利于开展自然资源形成、演化和规律等自然属性的科学研究。张风荣 ${ }^{[16]}$ 从自然 资源形成角度出发，分为原生资源（气候资源、矿产资源、岩石资源、土壤资源）和次 生资源（林草资源、作物资源、动物资源、水资源、土地利用/覆改）。间保银等 ${ }^{[2]}$ 则从 自然资源调查工作出发，将其划分为土地资源、水资源、草原资源、森林资源、湿地资 源、海洋资源、矿产资源等。还有学者 ${ }^{[33,34]}$ 从国土空间规划利用角度对自然资源进行了划 分。以上分类方案均主要面向狭义自然资源进行，而张文驹 ${ }^{[1]}$ 则以 “来源或功能” 二维 标准，提出了为更宏观的分类方案，拓展到了超越地球系统的广义自然资源范围。 
科学完整的自然资源分类应面向学科研究和业务组织管理的双重需要, 体现其科学 性和合理性 ${ }^{[16,35]}$ 。根据前人研究成果, 结合研究目的, 本文以地球系统科学理论为指导, 以固体地球系统为参考系，以与人类活动密切相关的资源实体为主要对象，以简洁、明 晰、实用为原则，提出基于自然资源空间和物质属性标准，服务于自然资源综合调查业 务的分类方案, 作为自然资源科学研究和构建综合调查业务体系框架的基础。首先按照 自然资源的空间属性，将其划分为地下空间、地表空间、低层空间和管理空间四个资源 层，再根据各资源层所赋存资源对象或实体划分不同的实体类型，以形成狭义陆域自然 资源的分类体系（图 1)。以下对此方案进行简单说明。

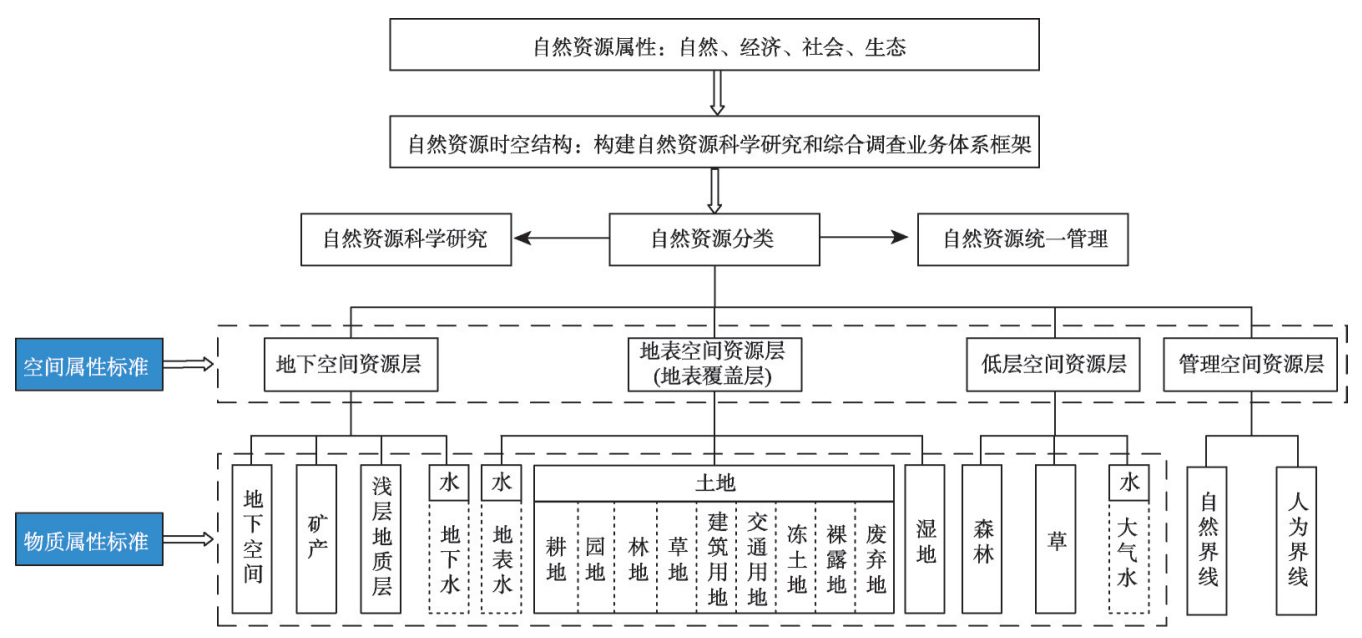

图 1 服务于综合调查业务的陆域自然资源分类方案

Fig. 1 Categorization scheme of territory natural resources serving comprehensive investigation

（1）分类方案涉及的空间是地球系统内的有限立体空间，即人类可能开发利用的自 然资源空间，受自然资源的经济和社会属性制约。自然资源在时间尺度上也是有限时间 内的资源，即目前在地球存在并在可预见的将来可被利用或对人类和生态有影响的资源。

（2）分类方案涉及的范围是狭义自然资源层次的有限资源，如光、风、温、热、气 和动物资源等暂未放人其中。这主要考虑到这些自然资源空间维度难以测定、时间变化 难以控制、物质属性难以描述或者人类主观判断大于客观自然存在, 更重要的是在目前 自然资源组织管理中还未提出明确要求, 难以资产化或登记为不动产等 ${ }^{[34]}$ 。另一方面, 由于海洋资源的特殊性及其自身特点，从自然资源调查监测和综合管理角度，宜独立构 建符合海洋资源特点和规律的业务框架体系，本方案没有涵盖。

（3）方案根据自然资源物质属性及相互关联，将地下空间、矿产、浅表地质层、土 地、水、森林、草和湿地等八种确定为陆域自然资源基本类（图 1)。在自然资源综合调 查和监测中, 需要建立自然资源时空结构模型, 通过立体调查方法与手段, 逐层查清各 类资源在不同空间的属性参数, 再通过逐层叠加, 才能实现对自然资源整体情况的掌握 了解和对自然资源的有序组织和科学管理。

（4）管理空间资源层实际上是自然资源在人类利用条件下的有序化、规范化的表现 和产物, 是自然资源经济社会属性的重要体现。人类一旦根据其需要对其掌握的自然资 源进行有序化和规范化规划，如确定边界、圈定范围、划分区片等，这些边界、范围、 
界线等所构成的实体就成为自然资源的一部分。虽是人类干扰条件下的产物，但本质上 仍具有自然资源的性质，是自然资源综合调查业务体系框架构建，特别是自然资源管理 职能中不可回避的问题。

（5）自然资源的穿时性、穿空性和多重性无法在有限的标准分类体系内得到全面体 现，内部嵌套、交叉并行和跨级并列的情况难以避免。随着科学研究的深人、人类经济 社会的发展和利用自然资源技术方法的进步，符合该分类标准原则的自然资源类型必定 会不断丰富; 自然资源组织管理和调查体系的改革深人，也会完善分类方案的结构。方 案中不同类型自然资源都可以根据研究和管理的需要，通过选用合适属性、标准或原 则, 进一步细化。

\section{2 时空属性结构}

\subsection{1 时间结构}

自然资源的时间结构是指自然资源在时间上的分布情况，表现为随时间演化而导致 存在状态和性质的改变，体现了人类对自然客观存在着的事物和现象价值的判断与评 价，包括了自地球诞生以来以及人类在地球上出现以来两个不同时间起点上发生的存在 状态和性质改变。简言之，自然资源的内涵和外延都是动态的，没有已知和固定的极 限。从旧石器时代到今天，自然资源种类随着人类社会和科学技术发展而不断扩展 (表2)，具有很强的时代性。

表 2 自然资源类型随人类社会和科学技术的发展而拓展（据蔡运龙 ${ }^{124}$ 修改补充）

Table 2 The changing and expanding of natural resource types with the development of human society

\begin{tabular}{|c|c|c|c|}
\hline 社会阶段 & 文化时期 & 人类技术水平 & 自然资源种类及变化 \\
\hline \multirow[t]{2}{*}{ 狩猎一采集社会 } & 旧石器时代 & 粗制石器、钻木取火 & 燧石、树木、鱼、兽、果 \\
\hline & 新石器时代 & 精制石器、刀耕火种 & 栽培植物、驯化动物 \\
\hline \multirow[t]{4}{*}{ 农业社会 } & 青铜器时代 & $\begin{array}{l}\text { 青铜斧、犁、冶铜技术、轮轴机械、灌溉技 } \\
\text { 术、木结构建筑 }\end{array}$ & 铜、锡矿石、耕地、木材、水流 \\
\hline & 铁器时代 & $\begin{array}{l}\text { 铁斧、犁、刀、冶铁技术、齿轮传动机械、 } \\
\text { 石结构建筑、水磨 }\end{array}$ & 铁、铅、金、银、泶、石料、水力 \\
\hline & 中世纪 & 风车、航海 & 风能、海洋水产 \\
\hline & 文艺复兴期 & 爆破技术 & 硝石（炸药与肥料） \\
\hline \multirow[t]{5}{*}{ 工业社会 } & 产业革命期 & 蒸汽机 & 煤 栗 \\
\hline & 殖民时期 & 火车、轮船、电力、炼钢、汽车、内燃机 & 石油、天然气 \\
\hline & 20 世纪初期 & 飞机、化肥 & 铝、磷、钾 \\
\hline & 20 世纪中期 & 人造纤维、核技术 & $\begin{array}{l}\text { 稀有元素、放射性元素; 石油和煤 } \\
\text { 不仅为能源, 也作为原料 }\end{array}$ \\
\hline & 20 世纪后期 & 空间技术、电子技术、生物技术等新技术 & $\begin{array}{l}\text { 更多金属、半导体元素、遗传基 } \\
\text { 因、硅 }\end{array}$ \\
\hline 现代社会 & 21 世纪 & 信息技术、人工智能、新材料与新能源技术 & $\begin{array}{l}\text { 地下空间、太阳能、风景和自然遗 } \\
\text { 迹环境质量、生态系统服务 }\end{array}$ \\
\hline
\end{tabular}

此外，人类活动的影响，也不同程度地干扰或改变了自然资源演化的过程和规律。 由此可见，自然资源的时间结构主要包括自然资源的种类变化、自然资源本身的自然演 变和人类影响下的状态改变三方面内容。

\subsection{2 空间结构}

自然资源的空间结构指自然资源在空间上的分布情况，具体表现为在不同空间条件 
下的存在形式和真实状态。地球系统作自然资源的载体, 是一个全维立体空间, 自然资 源作为实体在地球上占据一定的真实空间，在不同空间尺度上呈现出宏观有序、微观无 序，或此时有序、彼时无序，或兼而有之的分布状态 ${ }^{[30]}$ 。它们反映在二维平面上呈现出 复杂的交叉和重叠样式。自然资源综合调查的主要目的之一就是要查清自然资源在空间 上的分布情况，即空间结构。在整个地球空间系统中，目前应特别关注地壳浅部、地表 覆盖层和低层空间的有限资源问题。依此并结合管理需要，可将自然资源的空间结构划 分为地下空间、地表空间、低层空间和管理空间四个资源层，它们是地球水圈、生物 圈、大气圈和岩石圈交互作用最为剧烈和人与自然相互作用最为频密的空间范围。

（1）地下空间资源层：地下空间资源层主要是指地壳浅部 $0 \sim 10 \mathrm{~km}$ 范围的空间资源 层, 主要包括一定深度范围（人类向地下的探测深度已达 $12 \mathrm{~km}$ ，但人类开发利用的地 下空间主要在地下约 $2000 \mathrm{~m}$ 的范围）内的地下空间、作为其他资源载体的浅表地质层、 矿产和地下水、地热等。其中，地下空间指地面以下地质（岩土）体中天然存在或通过 人类改造形成的可供人类利用的安全空间, 尤以城市地下空间最重要; 浅表地质层, 又 称地表基质层，是孕育和支撑其他资源的地球浅表层物质，即岩土体的类型（如岩、 砾、沙、土等）及其表面形态（如山地、丘陵、平原、高原、盆地等），其向地下有一定 延深，但十分有限（一般不超过 $50 \mathrm{~m}$ )。它是地表空间层资源的根本和基础, 至关重 要; 矿产则包括了金属、非金属、能源、建筑材料和原料等多样化矿产，地热（包括地 下热流体和干热岩等）属能源矿产的一个子类，依赖于岩土体或水等存在; 地下水是特 指赋存在地下空间和物质内部的自由或非自由、连续或不连续、结构或非结构水体。地 下空间资源层所有资源的形成和演化是地球多样化内外部动力作用（风化、剥蚀、沉 积、岩浆、变质、构造等) 的产物, 很多受深部地球动力学过程控制。理解地球内部动 力学、深部动力学过程及其在不同时空尺度发生、发展和运动、演变规律, 是应对地下 空间所赋存资源和相关环境问题的根本所在。向深部要资源、要空间, 是未来人类生存 和社会发展的必然选择。需高度关注 $0 \sim 10 \mathrm{~km}$ 范围内的地壳精细结构与资源能源分布和 城市地下空间利用问题，为国家资源能源安全和经济社会发展提供基础支撑。

（2）地表空间资源层：地表空间资源层即固体地球表面层，又称地表覆盖层，是连 接地上低层空间和地下空间的纽带, 是人类赖以生存、生产和生活的主要基础, 该层自 然资源主要为土地和地表水以及它们的组合体。其中, 土地是最重要的, 也是分布面积 最广、功能最为多样化、结构最复杂的自然资源。土地主要由浅表地质层的上部物质组 成，但浅表地质层不等于土地。根据附着于土地的物质有无与不同，土地可分为湿地、 耕地（农地、农田）、林地、草地、建筑用地、交通用地、冻土地和裸露地（石漠、荒 漠、沙漠、戈壁）、废弃地等; 水域（地表水）包括覆盖在地球表面局部的江、河、湖、 海、池、塘、库、溪等液态水域和冰川、积雪等固态水域。湿地是一种特殊的由土和水 体及分布其上或附着于其内物质组成的复合资源，它既可以看成是土地资源的一个小 类，也可看成是与土地（即干地）、水域平行的资源类型。本文基于其生态功能特殊性, 将其单列出来，作为自然资源的一个基本类型。地球表面空间是联结气候系统一地表过 程一地球深部过程物质和能量循环的重要桥梁, 是固体地球内外部圈层强烈交互作用地 带, 是地球关键带的重要组成部分。全面系统查明地表空间资源状况和变化是自然资源 综合调查和监测的核心任务和主要内容。从地球系统科学角度出发, 探究地球表面层的 
结构、形成与演化机制、物质转化过程与相互作用, 研究人与自然相互作用和影响的机 理、规律、趋势和结果，对于合理开发、利用自然资源，改善和提升人类生态质量具有 重要意义。

（3）低层空间资源层：也可称为地上空间资源层，低层空间资源层指固体地球表面 以上 $(0 \sim 10 \mathrm{~km})$ 、大气圈的中下部空间层, 是附着于地表覆盖层之上相关自然资源的立 体空间层，凡占有一定量低层立体空间的自然资源都是该层资源的组成部分，包括森 林、草、农作物、水、气等。界定低层空间资源分布是确定相关自然资源生态功能量度 的实现途径, 是从生态功能的角度对各类自然资源的立体化细分。根据科学研究和综合 管理需要，可对每类资源根据其具体情况进一步划分，以获得相应的生态功能量值。如 森林资源，可以先划分为乔木林、竹林、红树林和特殊灌木林等，再依其树种组成与结 构等进一步细分；对农作物，可进一步划分为谷物、油料、菜田、棉花等。

（4）管理空间资源层：严格地说，管理空间资源层与上述三层不是并列关系，其实 质是人类对自然资源利用情况的反映，本质上是管理资源，是对客观自然资源实体的抽 象, 依赖于其他自然资源实体而存在, 并随它们的变化而变化, 主要特点是融合了人类 活动的影响。为了实现对自然资源及其占据空间的科学合理利用，在自然资源调查和监 测业务工作中，设立管理空间资源层是为了实现对实体自然资源生境演化空间的高效规 划和管理。根据地下、地表和低层空间资源情况, 结合人类活动需求, 叠加如行政区 划、地理单元、永久基本农田和生态保护地范围、城镇开发边界等界限数据, 可明确区 分自然资源的不同管控类型和范围。将自然资源进行满足人类需要的规划和管理，其经 济社会属性就明显突现。

\subsection{3 属性结构}

以上通过开展服务于自然资源综合调查监测工作的分类，明确了调查监测的基本对 象和实体，通过建立自然资源的时空结构，明确了调查监测工作时空坐标和尺度，基本 奠定了自然资源综合调查监测业务工作的基础。在具体调查监测工作中，还需要依据各 类自然资源的自然属性、经济社会属性和生态功能属性等特征, 分别建立起它们的要素 属性结构模型，以构成表征不同自然资源要素的综合指标体系。自然资源属性结构包括 通用属性和专用属性。通用属性是指各类自然资源具有的共性特征指标。以各类自然资 源体投射在地表的分布范围与位置等地理空间属性为主体, 以开发利用与保护情况等为 辅助，用来表征自然资源的基础或本底状态或状况。专用属性是指不同类型自然资源所 特有的特性信息指标，主要包括数量、质量、生态经济以及与其相关的信息等。根据本 文所提出的服务于综合调查业务的自然资源分类方案所确定的自然资源基本类型，其属 性特征结构综合列于如表 3 。

\section{3 自然资源综合调查业务体系框架}

我国长期以来对自然资源实行分头管理、各自为政的调查监测机制和体系，既不符 合 “山水林田湖草是一个生命共同体” 的宗旨，也不能满足新时代对自然资源实行统一 管理和开发利用的要求。着眼构建自然资源综合调查监测业务体系框架, 制定统一的自 然资源分类标准和调查规范，体系化、工程化、常态化、有序化推进自然资源调查监测 工作，已成为支撑自然资源综合管理、开发利用，实现自然资源整体保护、国土空间整 


\section{表 3 基本类型自然资源属性特征结构}

Table 3 Attribute structure of basic kinds of natural resources

\begin{tabular}{|c|c|c|c|c|}
\hline 基本类型 & 地理空间属性 & 数量属性 & 质量属性 & 生态经济及相关属性 \\
\hline 地下空间 & $\begin{array}{l}\text { 位置、类型、地表 } \\
\text { 的地形地貌和利用 } \\
\text { 功能指向、便利性 } \\
\text { 和施工条件 }\end{array}$ & $\begin{array}{l}\text { 适合开发的范围、可供开 } \\
\text { 发的面积、合理开发的深 } \\
\text { 度、地下可开发空间分层 } \\
\text { 性及资源量 }\end{array}$ & $\begin{array}{l}\text { 岩土体类型与结构、水文地 } \\
\text { 质结构、构造稳定性和地面 } \\
\text { 沉降等 }\end{array}$ & $\begin{array}{l}\text { 地面沉降、地下水位的 } \\
\text { 变化、可能引起的地下 } \\
\text { 污染状况 }\end{array}$ \\
\hline 矿产 & $\begin{array}{l}\text { 空间位置、分 } \\
\text { 布、产状, 开发 } \\
\text { 利用状态 }\end{array}$ & 资源量或储量 & $\begin{array}{l}\text { 种类, 矿体形态、结构和规 } \\
\text { 模, 矿石类型、结构和品 } \\
\text { 位, 矿物和化学成分, 共伴 } \\
\text { 生元素及其可综合利用性, } \\
\text { 自然秉赋和采选冶条件等 }\end{array}$ & $\begin{array}{l}\text { 土地破坏、环境污染、 } \\
\text { 水土流失、次生地质灾 } \\
\text { 害、人类健康 }\end{array}$ \\
\hline $\begin{array}{l}\text { 浅表 } \\
\text { 地质层 }\end{array}$ & $\begin{array}{l}\text { 位置、空间分布 } \\
\text { 与形状，地理表 } \\
\text { 观特征 }\end{array}$ & $\begin{array}{l}\text { 物质成分、面积、厚（深 } \\
\text { 度）、体积 }\end{array}$ & $\begin{array}{l}\text { 物理、化学状态, 结构构造 } \\
\text { 特征, 含水性等 }\end{array}$ & $\begin{array}{l}\text { 本身的生态经济贡献 } \\
\text { 值, 对其他资源的支 } \\
\text { 撑、孕育能力和地域性 } \\
\text { 差异 }\end{array}$ \\
\hline 土地 & $\begin{array}{l}\text { 位置、分布和形 } \\
\text { 状, 开发利用状态 }\end{array}$ & 类型；面积、厚 (深) 度 & $\begin{array}{l}\text { 等级、物质成分、孔隙度和 } \\
\text { 含水性、健康状况、种植条 } \\
\text { 件、粮食产量、可利用情 } \\
\text { 况、承载能力等 }\end{array}$ & $\begin{array}{l}\text { 耕地保有量、资源承载 } \\
\text { 和人类利用的适宜度和 } \\
\text { 可利用度 }\end{array}$ \\
\hline 水 & $\begin{array}{l}\text { 位置、分布、范 } \\
\text { 围、水体形状， } \\
\text { 开发利用状态 }\end{array}$ & $\begin{array}{l}\text { 水域面积、总量、分类资源 } \\
\text { 量、可利用资源量以及开发 } \\
\text { 利用现状, 水位、径流量, } \\
\text { 地下水水位、涌水量 }\end{array}$ & $\begin{array}{l}\text { 自然状态、水质、产能（水 } \\
\text { 能蕴藏量）等 }\end{array}$ & $\begin{array}{l}\text { 水域面积率、地下水超采 } \\
\text { 面积比、生态功能以及开 } \\
\text { 发利用对生态的影响 }\end{array}$ \\
\hline 森林 & $\begin{array}{l}\text { 位置、空间分布 } \\
\text { 及范围 }\end{array}$ & $\begin{array}{l}\text { 林种数量、分布面积、覆盖 } \\
\text { 率、蓄积量、郁闭度、生长 } \\
\text { 量, 树高、胸径、年龄 }\end{array}$ & $\begin{array}{l}\text { 起源、群落及其结构、龄 } \\
\text { 组、郁闭度、功能、材积、 } \\
\text { 林业产量总产值等 }\end{array}$ & $\begin{array}{l}\text { 生物量、碳储量、涵养水 } \\
\text { 源、保护水土、美化环 } \\
\text { 境、净化空气、多样性 }\end{array}$ \\
\hline 草 & $\begin{array}{l}\text { 位置及边界、范 } \\
\text { 围, 草原地形与 } \\
\text { 地貌景观 }\end{array}$ & $\begin{array}{l}\text { 面积、综合植被覆盖度、 } \\
\text { 疏密度、生物 量、产草 } \\
\text { 量、草群种类、草群平均 } \\
\text { 高、等级 }\end{array}$ & $\begin{array}{l}\text { 草群结构、等级、草原植被 } \\
\text { 生长状况、毒害草种类及占 } \\
\text { 比、利用状况、草地生产 } \\
\text { 力、草原载蓄量与载蓄能 } \\
\text { 力等 }\end{array}$ & $\begin{array}{l}\text { 调节气候、防风固沙、 } \\
\text { 涵养水源、保护水土、美 } \\
\text { 化环境、净化空气和防治 } \\
\text { 公害、维持生物多样性和 } \\
\text { 营造草原生态景观 }\end{array}$ \\
\hline 湿地 & $\begin{array}{l}\text { 位置、分布、地 } \\
\text { 形与海拔、边界 } \\
\text { 与形状 }\end{array}$ & $\begin{array}{l}\text { 面积、大小、范围、湿地 } \\
\text { 率、湿地保护率以及组成 } \\
\text { 湿地各要素的数量属性 }\end{array}$ & $\begin{array}{l}\text { 类型、水文系统变化、生物 } \\
\text { 多样性、保护与利用、受威 } \\
\text { 胁状况, 以及组成湿地各要 } \\
\text { 素的质量属性等 }\end{array}$ & $\begin{array}{l}\text { 保护生物多样性、调节 } \\
\text { 径流、改善水质、调节 } \\
\text { 小气候、涵养水源、蓄 } \\
\text { 洪防旱、降解污染、补 } \\
\text { 充地下水和水土防护 }\end{array}$ \\
\hline
\end{tabular}

体规划和生态环境综合治理的当务之急。

\section{1 基本思路与流程}

自然资源综合调查是国家公益性、基础性工作，涉及面广、涵盖领域宽、服务对象 多、标准要求高, 体系庞大且复杂, 是一项系统工程。所获取的数据敏感性强, 是自然 资源部代表国家履行全民所有自然资源资产所有者职责、实施国土空间用途管制和科学 规划、保障国家生态安全的重要支撑, 是国家实现治理体系和治理能力现代化的重要保 障，反映了国家所拥有自然资源的基本情况、自然秉赋、真实家底和开发利用现状，一 定程度上展现了国家综合实力、资源利用潜力和发展前景。自然资源综合调查工作应以 国家需求为导向，以助力自然资源统一管理、国土空间规划和生态环境综合治理为目 标，以服务各级各类政府机构部门和人民需要为宗旨，按照自然资源生成、演替和发展 的客观规律，顶层设计、周密筹划、科学部署、部门协作、共同推进。其业务体系构建 
应坚持基础先行、调查为本、动态掌控、数据准确、成果真实、注重创新和聚焦应用为 原则，努力做到各阶段各环节工作内容清晰、工作周期节奏把握到位、全工作流程科学 合理。

基于自然资源分类体系和属性结构特征，本文构建自然资源综合调查业务体系框架 的基本思路是：在进一步完善自然资源综合调查法规制度体系基础上和科技创新体系支 撑下，通过体系化制定符合新时代自然资源调查工作要求的标准规范，多要素统一调查 与单要素专项调查相衔接, 周期性常规调查和长期性跟踪监测相协调, 定期获取和动态 更新调查监测数据，全新搭建自然资源大数据管理平台，分层分类分区分级和统一集中 管理数据信息相结合，以现代信息技术为支撑，创新先进的理论、方法与技术，开展多 元异构数据处理、融合、集成、分析和评价, 开发层次分明、形式多样、特色鲜明的成 果产品体系，全方位、全流程、全维度支撑服务政府、社会、行业、公众等多元化需求。

\section{2 业务工作及基本要求}

从图 2 可以看出, 自然综合调查业务基本流程由统一（基础）调查和专项调查、动 态监测和数据更新、数据管理和综合 集成、成果表达与应用服务等主要业 务和标准规范建设与科技创新贯彻全 流程的支撑业务等组成，不同业务工 作及其基本要求如下。

\section{2 .1 统一(基础)调查}

（1）定位与特点：统一调查又称 基础调查，是指根据自然资源时空结 构模型，针对自然资源基本类及其通 用属性，多要素一体开展的统一调查 工作，处于业务体系中的基础层次。 基本定位是国家重大国情国力调查的 基础性、公益性、前瞻性和战略性工 作；基本特点是整体部署、分区推 进、快速完成，周期性实施、全国土 覆盖、全要素一体。

（2）目的和任务：全面掌握国 家自然资源基本类型本底状况和共 性特征, 旨在摸清家底、了解现 状、把握宏观，以形成覆盖全国陆 表范围自然资源 “一张图”为目 标, 为专项调查、动态监测和深化 研究提供基础性数据信息，为资源 管理、国土规划、空间管制和生态 保护等提供宏观服务。

（3）内容和重点：以各自然资源 基本类的空间分布、覆盖范围和面积

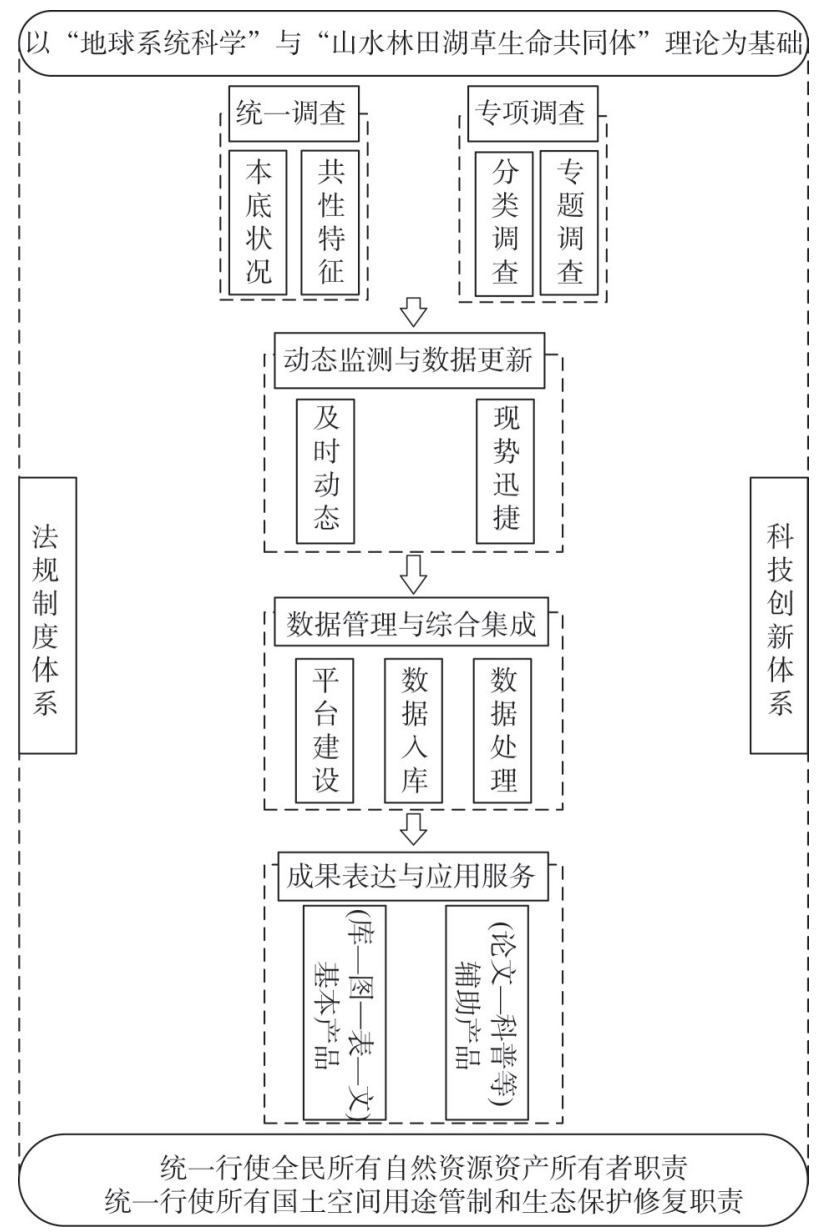

图2 自然资源综合调查业务基本流程

Fig. 2 Flow chart of comprehensive investigation of natural resources 
数量等为核心内容，重在查明不同类型自然资源体在地表的投射状态、相互之间的空间 位置关系、以及整体开发利用和保护基本情况，特别关注相邻两次调查数据和状态的变 化情况。

（4）范围和精度：工作针对全国展开，可考虑按国际标准分幅联测或省市区区划综 合调查进行部署, 以 $1: 25$ 万 1 : 50万为主体比例尺。根据国家需要灵活确定调查周期 (如 10 年), 为保证基础调查成果的现势性，以 $2 \sim 3$ 年为一次调查项目工作周期，确定全 国统一调查时空基准，充分吸收 “国土三调” 等全国性调查工作经验做法，成立专门组 织领导机构，统一部署、全国联动、整体推进、快速 “出数”。在一个调查周期的其余时 间内，转人动态监测和数据更新工作。

（5）方法与手段：在全面应用前期各类资源调查数据成果基础上，充分利用遥感信 息技术、地理信息系统等高新技术，以高精度空间分辨率卫星、航空多源遥感信息解译 提取和室内综合判读为主要手段, 辅以必要的野外修定、补测、查证、核实, 快速完成 调查任务，按时提交调查成果。

\section{2 .2 专项调查}

(1) 定位与特点：专项调查包括分类调查和专题调查。分类调查是指在全国性统一 调查基础上, 根据国家需要, 专门针对某单一类型自然资源（如森林、草等）开展的专 业性调查工作 ${ }^{[37-39}$; 专题调查是指在全国性统一调查基础上，根据国家重大战略、重大需 求、重要工程等特殊性要求, 以特定区域或范围（如长江经济带、京津冀协同发展区 等）为重点, 开展的专题性调查工作。与分类调查针对某单一类型资源不同，专题调查 应该包括调查区内出现的所有自然资源基本类，可称为 “小统一” 调查。其基本定位是 公益性和基础性，主要特点是重点突出、目标明确、内容专业、指标完整。

(2) 目的和任务: 分类调查旨在精确掌握国家各类型自然资源数量、质量及其对于 生态环境建设的贡献值，准确把握不同类型自然资源成生、演替、变化趋势和发展规 律，科学研判相关自然资源对国家经济社会发展、生态文明建设和满足人民生产生活需 求的保证程度，为国家制定自然资源管理、保护、开发、利用专项政策和出台法制规章 等提供详实的数据信息支撑。专题调查则是深度查明相关区域或流域不同类型自然资源 具体情况、时空结构及组合配置情况，详细摸清相应地区各类自然资源秉赋特征和开发 利用条件, 支撑研究相应地区不同类型自然资源相互作用、相互反馈及开发利用对生态 环境影响的内在机制、特点规律，正确评价自然资源对支撑国家重大战略实施等的承载 能力、保障能力和持续潜力, 为科学制定相应地区社会经济发展规划、国土空间管理控 制和开发使用方案、设计生态环境保护和修复方案、提升人民生活水平和幸福指数措 施、保障人与自然和谐共生和发展策略, 保证国家重大战略贯彻实施、重大工程建设运 用等提供精准服务。

（3）内容与重点：分类调查主要调查某单一类型的自然资源，可以根据具体需求确 定调查的主要指标或属性（如森林蓄积量、草生物量等）；而专题调查则结合调查区实际 情况，在整体查明相应地区所有类型自然资源重要指标基础上，重点关注主要自然资源 类型以及它们间相互作用、相互影响的机制和规律等。

（4）范围和精度：专项调查与统一调查相比，范围明显不同，精度普遍提高。分类 调查根据需求，可以在全国范围内开展，也可在国家和地方关注的部分区域或流域开 展。如全国森林蓄积量调查虽然在全国范围内开展，但重点是乔木林区; 湿地调查既可 
以是全国性的，也可以是区域性的; 地下空间调查则主要针对特大、超大型和大城市开 展; 矿产资源调查可根据国家经济社会发展不同阶段、国际国内矿产市场形势、国家安 全和国防需要等分别有不同的调查对象、区域和重点。专题调查的范围一般与国家重点 战略和工程部署规划的范围一致, 围绕工作目标确定重点调查内容。专项调查一般需要 有较高的精度, 比例尺普遍大于 $1: 5$ 万, 甚至 $1: 1$ 万或 $1: 5000$, 局部地区可能需达到 更大比例尺。

（5）方法和手段：专项调查工作一般以重大专项和专题任务组织部署、工程化实 施。在充分对接需求前提下, 根据工作内容和重点, 科学确定调查周期或时限, 选择合 理的方法技术、手段或其组合。以前人调查数据和理论研究成果为基础, 将现代高新技 术应用贯穿始终; 野外实地调查和实验测试等必不可缺。调查抽样、路线布设、剖面测 量、样点观测等方法应保证足够的代表性和科学性，以支撑数据采集的准确性、全面性 和真实性; 专项调查中应特别注重科技创新。

\section{2 .3 动态监测与数据更新}

(1) 定位与特点: 动态监测是指在统一调查与专项调查基础上, 对自然资源有关属 性指标变化情况及其连锁反应的动态跟踪和记录。根据监测内容, 可分为综合监测和专 项监测 ; 根据监测时间，可分为定期监测和不定期监测；根据监测手段可分为航天 （空）（遥感）监测、地面定点实时监测和远程监测；根据监测要求可分为重点监测和一 般监测等。监测工作伴随着数据更新, 应将监测所获取的数据及时更新到调查工作所建 立的数据库中。实时动态监测是了解两个调查周期间自然资源相关属性指标变化和年度 变更的重要手段, 其基本定位也是国家公益性、基础性、长期性工作; 基本特点是实时 性强、现势性好、动态更新和迅捷服务。

（2）目的与任务：实时跟踪和及时掌握自然资源各属性指标变化, 动态更新和完善 数据库, 综合预判发展演化趋势, 及早发现可能引发的国土空间安全和生态环境隐患或 问题，有效服务督察执法和动态监管，支撑制定和形成应对策略和处理方案。

(3) 内容和重点: 根据自然资源统一管理需要, 科学设定监测内容与指标, 突出不 同类型自然资源易随时间和外在环境变化而发生改变的各种属性，主要关注重点区域、 关键时段、重要节点和特殊条件下的属性变化情况，以增强监测的有效性和针对性。

（4）范围与精度: 根据具体需要进行明确。

（5）方法和手段：目前，我国各有关部门和行业已经针对各自工作需要，分别建立 和形成了不同层次、不同地区、各有侧重的监测站点和网络，但不同监测平台、站点和 网络之间的协同联动和综合监测能力没有形成。当务之急是充分依托现有监测平台建设 成果和已有条件, 从顶层进行整合和融合相关资源和队伍，打通部门和行业壁垒，统一 规范标准要求, 通过升级、改造、扩能、补点等措施, 逐步形成星空地海多平台配套、 陆地海洋和地上地下空间布局合理、山水林田湖草等多要素一体、建设一监测一运维体 系健全、数据成果多部门共享的开放式自然资源要素监测网络, 努力形成综合监测和专 项监测相得益彰、长期连续观测和重点监测并行不悖的良性格局。

\subsection{4 数据管理与综合集成}

(1) 定位与特点: 数据管理和综合集成是新时代自然资源综合调查业务体系的重要 环节, 是自然资源大数据体系建设的基础支撑和连接综合调查与服务应用的纽带。需要 从更高的站位、更高的角度审视和规划数据管理和综合集成问题，致力破解当前数据分 
散管理和行业垄断、平台交叉或重复建设、推送传输和共享困难、数据信息难以有效挖 掘、功能作用不能充分发挥、综合集成难以操作和实现的局面 ${ }^{[40]}$ 。数据管理、处理、使 用、发布和综合集成工作等很大程度上属于政府职能，但需要政府部门、企事业单位、 科研机构等广泛参与，其基本定位是公益性和社会性，具有很强的创新性和专业性。

(2) 目的与任务: 对调查监测数据进行有效组织和管理, 针对多样化需求, 开展专 业化和定制化处理及集成分析等工作，为形成形式多样、体系配套、层次清晰、特色鲜 明的产品奠定基础。

（3）内容与重点：面向自然资源统一管理要求，科学设计自然资源数据库结构，确 保各类调查监测数据能及时人库、存储、查询和更新; 全新构建自然资源数据时空模 型, 建立跨部门、跨领域的数据管理平台和业务网络, 充分兼容已有历史数据和成果, 实现对自然资源数据的统一组织、统一管理和集成调用; 以自然资源调查成果应用为导 向, 开展自然资源数据的分类整理、专业处理、统计分析、集成创新和综合评价等工 作，形成不同层次的初级产品、中间产品和成果产品，适时发布自然资源调查监测成果。

（4）方法与手段：以自然资源科学领域最新理论为指导，围绕国家大数据战略，以 现代计算机、大数据、云计算、物联网和区块链等先进技术为主要方法和手段，以稳定 流畅、高效智能、功能全面、界面友好的信息系统为平台, 进行自然资源数据管理和综 合集成的组织与实施，努力实现自然资源统一管理和社会服务现代化。按照平台建设是 基础支撑、数据人库是核心工作、数据处理是常态业务、共享共用是方向目标的原则, 加强数据集成和综合整理工作。

\section{2 .5 成果表达与应用服务}

（1）定位与特点：组织开展自然资源综合调查，及时向社会发布产品成果，以满足 不同层次、不同部门和行业应用服务需求，是自然资源综合调查业务工作的根本目的， 也是相关部门和单位的职能使命所在。成果表达和应用服务是自然资源综合调查业务的 “最后一公里” 工程，具有形式多样、体系配套、统一规范、方便迅捷等基本特点。

(2) 目的与任务：根据自然资源统一管理和部门、行业、领域等不同需求，结合自 然资源自身特点规律和学科建设发展需要, 依托自然资源综合调查和监测数据, 研制、 生产并发布成果产品; 有序、按规、及时向社会提供高效的应用服务和支撑保障。

（3）内容与重点：构建以 “库一图一表一文” 为主体的基本产品和以学术论文和著 作、科普文献、汇报请示、政策建议等为辅助产品的自然资源综合调查成果产品结构。 “库” 是指覆盖自然资源综合调查全部业务工作及由此产生的各类数据集和数据库; “图” 和 “表” 是根据不同类型自然资源特点属性, 以数据库为基础形成的各类系列图件 和表单; “文” 是指在自然资源调查工作过程中形成的项目总结报告、专题成果报告、分 析评价报告或说明书等。规范成果管理和向社会提供服务的机制、方法、途径和形式， 建立成果产品服务、保障、应用效果和绩效的评价和反馈机制，切实发挥调查成果对国 家制定自然资源领域重大方针政策、出台相关战略和措施、提高自然资源科学研究水平 等的支撑保障作用。

（4）范围与要求：对于统一性和公开性成果，需规范成果发布机制，按照程序和保 密要求, 严格成果发布机构、形式、时间、内容、范围和渠道。对于专业性和特色性成 果则按需定制、专线推送和提供服务。 
（5）方法与手段：自然资源调查系列成果的形成和应用服务需运用专业化的方法、 手段和工具，不同的成果产品可形成于自然资源调查工作的不同阶段。分布式数据库建 设是统一集成、网络调用多元异构数据库的必备软件；基于统一空间基准的地理信息系 统是开展带有空间结构属性自然资源数据组织管理、拓扑运算、缓冲分析、叠加展示和 三维可视化的有力工具。在对自然资源调查监测数据进行统计、分析、评价和决策中, 广泛应用到数学建模、模拟计算、专家系统、信息挖掘和人工智能等先进技术或工具; 数据驱动的制图技术将是自然资源领域各类图件制作的必然趋势。

\section{2 .6 标准规范建设和科技创新}

新时代自然资源综合调查是一项全新的事业，它既是对过去传统调查业务的继承发 展，更是面向自然资源统一管理和国土空间统一规划管制的实践创新。有效保障和顺利 推进自然资源综合调查各项业务，需从自然资源综合调查工作的全局性、系统性、整体 性和科学性角度, 深人探索并顶层规划标准规范、科技创新、质量保证、人才装备以及 体制机制等业务支撑体系建设。其中，人才队伍和装备、体制机制建设和组织实施与质 量控制主要是管理层面的问题。以下主要就标准规范建设和科技创新等技术层面的问题 进行简要讨论。

（1）标准规范建设：统一的标准规范是新体制下开展自然资源综合调查的重要前 提 ${ }^{[41]}$ 。应在深人研究自然资源综合调查业务工作体系结构和特点规律基础上，针对不同 工作环节、工作内容，开展自然资源综合调查标准规范体系顶层设计，以自然资源综合 调查业务体系框架和基本流程为牵引，按照 “体系设计、急用先建、分步组织” 原则， 制定并逐步完善由基础标准、调查标准、监测标准、数据标准、产品标准、服务标准和 管理标准等组成的自然资源综合调查标准体系，根据标准规范建设的基本程序和要求， 适时出台相关工作指南、作业规程、技术要求、建设规范等，以有效支撑自然资源综合 调查的相关工作。

（2）科技创新工作：自然资源统一调查和管理是贯彻新时代生态文明建设思想、完 善国家管理体制的重大创新。应运而生的自然资源综合调查, 涉及复杂的地球层圈系 统, 涵盖广泛的自然科学和社会科学领域。且不说各单一自然资源学科本身都还存在许 多重大科学技术问题需要依靠科技创新进行攻关突破, 将众多自然资源学科进行整合, 更需要在研究不同类型自然资源之间、人与自然资源之间相互作用、相互制约、相互影 响的基本理论和原理、机制与规律、变化与趋势，及其对流域、区域甚至全球生态的响 应和效应等理论方面加强创新 ${ }^{[42]}$ 。此外, 自然资源综合调查又是一种实践性很强的技术 工作，几乎涉及到现代先进技术的方方面面，从航天遥感到深地探测、从遥远感知到实 地调查、从模型模拟到实验测试、从理念推导到逻辑演绎、从统计分析到集成融合、从 数据挖掘到信息提取、从大数据到物联网、从云端计算到人工智能等等，也离不开技术 创新支撑。针对自然资源领域重大关键科学问题，设立科技创新专项，集中精力推动自 然资源组合与时空变化规律、自然资源综合调查监测技术支撑体系、资源开发利用与生 态环境响应反馈、地球关键带过程作用与功能、资源环境承载力评价与国土空间适宜性 评价、生态环境变化趋势和重大自然灾害预测预报预警与应对策略等关键技术理论攻 关, 占领自然资源科学理论与技术研究制高点, 应该贯穿于自然资源调查业务体系全流 程之中。 


\section{4 结论}

（1）自然资源具有广义和狭义之分。作为综合调查客观对象和实体的自然资源，通 常是指狭义层次上的有限资源，即客观存在于地球系统中并能为人类利用的空间、物质 和能量等自然环境要素及其组合, 具有自然属性、经济属性、社会属性和生态属性等多 种基本属性。

（2）提出现阶段支撑和服务自然资源综合调查业务的分类方案。将陆域自然资源划 分为地下空间、地表空间、低层空间和管理空间等 4 个资源层，确定地下空间、矿产、 浅表地质层、土地、水、森林、草和湿地等作为自然资源综合调查的 8 个基本类。

（3）建立了自然资源基本类型的时空和属性结构模型。不同类型自然资源既有用来 表征其基础和本底状态或状况的通用属性指标，同时又具有反映各自差异的数量、质 量、生态（包括经济的）以及与其相关的地理信息情况等专用属性指标。

（4）基于自然资源分类体系和属性结构，探索构建了自然资源综合调查业务体系框 架。强调标准规范建设和科技创新工作应贯穿于统一调查一专项调查一动态监测和数据 更新一数据管理与综合集成一成果表达与应用服务基本流程和各项业务工作之中。

\section{参考文献(References):}

[1] 万年庆, 罗焕枝, 刘学功. 对自然资源概念的再认识. 信阳师范学院学报: 自然科学版, 2008, 21(4): 630-634. [WAN N Q, LUO H Z, LIU X G. The new comprehension about the definition of the natural resources. Journal of Xinyang Normal University: Natural Science Edition, 2008, 21(4): 630-634.]

[2] 王庆礼, 邓红兵, 钱俊生. 略论自然资源的价值. 中国人口・资源与环境, 2001, 11(2): 25-28. [WANG Q L, DENG H B, QIAN J S. On the values of natural resources. China Population, Resources and Environment, 2001, 11(2): 25-28.]

[3] 李文华. 《中国自然资源通典》介绍. 自然资源学报, 2016, 31(11): 1969-1970. [LI W H. Introduction of Dictionary of Chinese Natural Resource. Journal of Natural Resources, 2016, 31(11): 1969-1970.]

[4] 谢高地, 封志明, 沈镭, 等. 自然资源与环境安全研究进展. 自然资源学报, 2010, 25(9): 1424-1431. [XIE G D, FENG Z M, SHEN L, et al. Research progress in natural resources and environmental security. Journal of Natural Resources, 2010, 25(9): 1424-1431.]

[5] 沈镭, 张红丽, 钟帅, 等. 新时代下中国自然资源安全的战略思考. 自然资源学报, 2018, 33(5): 721-734. [SHEN L, ZHANG H L, ZHONG S, et al. Strategic thinking on the security of natural resources of China in the New Era. Journal of Natural Resources, 2018, 33(5): 721-734.]

[6] 杜文鹏, 间慧敏, 杨艳昭. 自然资源资产负债表研究进展综述. 资源科学, 2018, 40(5): 875-887. [DU W P, YAN H M, YANG Y Z. A review of natural resource asset balance sheets. Resources Science, 2018, 40(5): 875-887.]

[7] FENG Z M, LI F Z, YANG Y Z, et al. The past, present, and future of population geography in China: Progress, challenges and opportunities. Journal of Geographical Sciences, 2017, 27(8): 925-942.

[8] MATHEIS M. Natural resource extraction and mortality in the United States. Journal of Environmental Management, 2019, 235: 112-123.

[9] 于琳倩, 李景文, 李俊清, 等. 中国沙漠、戈壁自然资源分类体系及其组成特点. 内蒙古农业大学学报: 自然科学版, 2014, 35(1): 59-66. [YU L Q, LI J W, LI J Q, et al. Classification and specialty of the natural resources in the desert and gobi ecosystem in China. Journal of Inner Mongolia Agricultural University: Natural Science Edition, 2014, $35(1)$ : 59 66.]

[10] HOU Z Q. Thinking on improvement of natural resources management. China Geology, 2018, 1: 2-4.

[11] 张文驹. 自然资源一级分类. 中国国土资源经济, 2019, 32(1): 4-14. [ZHANG W J. The classification for natural resources. Natural Resource Economics of China, 2019, 32(1): 4-14.]

[12] 王伟. 自然资源类型统一分类指标研究. 中国矿业, 2018, 27(6): 66-69. [WANG W. Study on the unified classification index of natural resource types. China Mining Magazine, 2018, 27(6): 66-69.]

[13] 杨静, 张德礼. 适应自然资源统一管理的林地调查标准研究. 上海国土资源, 2018, 39(3): 69-72. [YANG J, ZHANG D L. Study on the standards of forestland investigation for the unified management of natural resources. Shanghai Land \& Resource, 2018, 39(3): 69-72.] 
[14] 习近平. 推动我国生态文明建设迈上新台阶. 求是, 2019, 62(3): 4-19. [XI J P. Promoting the construction of ecological civilization in China to a higher level. Truth Seeking, 2019, 62(3): 4-19.]

[15] 王占宏, 白穆, 李宏建. 地理空间大数据服务自然资源调查监测的方向分析. 地理信息世界, 2019, 26(1): 1-5. [ZHANG Z H, BAI M, LI H J. Direction analysis on service for natural resource investigation and monitoring using geospatial big data. Geomatics World, 2019, 26(1): 1-5.]

[16] 张凤荣. 建立统一的自然资源系统分类体系. 中国土地, 2019, (4): 9-10. [ZHANG F R. On establishing unified classification system of natural resources. China Land, 2019, (4): 9-10.]

[17] 陈征. 自然资源价值论. 经济评论, 2005, (1): 3-6. [CHEN Z. A theory of natural resources value. Economic Review, 2005, (1): 3-6.]

[18] ZIMMERMANN E W. World Resources and Industies: A Functional Appraisal of the Availability of Agricultural and Industrial Resources (1951 Rev. Ed.). New York: Harper \& Row Publishers, 1933.

[19] United Nations Environment Programme. U. N. Conference on Human Environment - Stockholm, Sweden, June 20-26, 1972.

[20] 辞海编辑委员会. 辞海(缩印本). 上海: 上海辞书出版社, 1980. [Editorial Board of Cihai. Cihai (Abbreviated Edition). Shanghai: Shanghai Lexicographic Publishing House, 1980.]

[21] 李文华, 沈长江. 自然资源科学的基本特点及其发展的回顾与展望. 见: 自然资源研究的理论和方法. 北京: 科学出 版社, 1985: 1-23. [LI W H, SHEN C J. Review and prospect of the basic characteristics and development of natural resources science. In: Theory and Method of Natural Resources Research. Beijing: Science Press, 1985: 1-23.]

[22] 孙鸿烈. 中国自然资源科学百科全书. 北京: 中国大百科全书出版社\&石油大学出版社, 2000. [SUN H L. China Encyclopedia of Resources Science. Beijing: Encyclopedia of China Publishing House \& University of Petroleum Press, 2000.]

[23] 封志明. 资源科学导论. 北京: 科学出版社, 2004. [FENG Z M. Introduction to Resources Science. Beijing: Science Press, 2004.]

[24] 蔡运龙. 自然资源学原理. 北京: 科学出版社, 2018. [CAI Y L. Principium of Natural Resources Sciences. Beijing: Science Press, 2018.]

[25] 自然资源部. 自然资源调查监测体系构建总体方案. 2020: 1-25. [Ministry of Natural Resources of the People's Republic of China. Scheme for the construction of natural resources investigation and monitoring system. 2020: 1-25.]

[26] 张文驹. 国土资源行政管理的若干应用基础理论问题(上): 自然资源属性分析. 中国地质矿产经济, 2003, 16(1): 47. [ZHANG W J. Several problems on basic applied theory of land and resources administration (part 1): Analysis on attribute of natural resources. China Geology \& Mining Economics, 2003, 16(1): 4-7.]

[27] 李克强. 论可再生自然资源的属性及其产权. 中央财经大学学报, 2008, (12): 68-73. [LI K Q. On the attributes and property rights of renewable natural resources. Journal of Central University of Finance \& Economics, 2008, (12): 6873.]

[28] 成金华, 尤喆. “山水林田湖草是生命共同体”原则的科学内涵与实践路径. 中国人口·资源与环境, 2019, 29(2): 16. [CHENG J H, YOU Z. Scientific connotation and practical paths about the principle of "taking mountains, rivers, forests, farmlands, lakes, and grasslands as a life community". China Population, Resources and Environment, 2019, 29(2): 1-6.]

[29] 柇笑英. 自然资源资产负债表中的生态价值体现. 中国国土资源经济, 2019, 32(3): 34-37. [FAN X Y. The expression of ecological value in natural resources balance sheet. Natural Resource Economics of China, 2019, 32(3): 34-37.]

[30] 孙九林, 孙晓华. 自然资源信息分类体系. 自然资源, 1989, (2): 62-69. [SUN J L, SUN X H. Classification system of natural resource information. Natural Resources, 1989, (2): 62-69.]

[31] HAGGETT P. Geography: A Global Synthesis. Edinburgh Gate: Pearson Education Limited, 2001.

[32] 间保银, 崔立. 基于土地资源调查的自然资源统一调查方案. 现代农业科技, 2018, (22): 291-292. [YAN B Y, CUI L. Based on unified investigation plans of natural resoureces of land. Modern Agricultural Science and Technology, 2018, (22): 291-292.]

[33] 陈长成, 邓木林, 朱江. 面向国土空间规划的自然资源分类. 国土与自然资源研究, 2019, (5): 9-14. [CHEN Z C, DENG M L, ZHU J. Classification of natural resources for spatial planning. Territory \& Natural Resources Study, 2019, (5): 9-14.]

[34] 孔雷, 唐芳林, 刘绍娟, 等. 自然资源类型和类别划分体系研究. 林业建设, 2019, (2): 20-27. [KONG L, TANG F L, LIU S J, et al. Research of classification system of natural resources types and categories. Forestry Constraction, 2019, (2): 20-27.]

[35] 马永欢, 吴初国, 苏利阳, 等. 重构自然资源管理制度体系. 中国科学院院刊, 2017, 32(7): 757-765. [MA Y H, WU C 
G, SU L Y, et al. Reshaping natural resources management system. Bulletin of the Chinese Academy of Sciences, 2017, 32(7): 757-765.]

[36] 应申, 李程鹏, 郭仁忠, 等. 自然资源全要素概念模型构建. 中国土地科学, 2019, 33(3): 50-58. [YING S, LI C P, GUO R Z, et al. Conceptual model construction of natural resource full factors. China Land Science, 2019, 33(3): 5058.]

[37] 叶远智, 张朝忙, 邓轶, 等. 我国自然资源、自然资源资产监测发展现状及问题分析. 测绘通报, 2019, (10): 23-29. [YE Y Z, ZHANG C M, DENG Y, et al. Research on the current situation and problems of natural resources monitoring and natural resources assets monitoring in China. Bulletin of Surveying and Mapping, 2019, (10): 23-29.]

[38] 崔巍. 对自然资源调查与监测的辨析和认识. 现代测绘, 2019, 42(4): 17-22. [CUI W. Discrimination and recognition of investigation and monitoringof natural resources. Modern Surveying and Mapping, 2019, 42(4): 17-22.]

[39] 吴凤敏, 胡艳, 陈静, 等. 自然资源调查监测的历史、现状与未来. 测绘与空间地理信息, 2019, 42(10): 42-44. [WU F M, HU Y, CHEN J, et al. History, current situation and future of natural resources survey and monitoring. Geomatics \& Spatial Information Technology, 2019, 42(10): 42-44.]

[40] 马永欢, 吴初国, 林慧, 等. 完善全民所有自然资源资产管理体制研究. 中国科学院院刊, 2019, 34(1): 60-70. [MA Y H, WU C G, LIN H, et al. Research on perfecting management system of state-owned natural resources assets. Bulletin of the Chinese Academy of Sciences, 2019, 34(1): 60-70.]

[41] 吴恒, 唐芳林, 刘绍娟, 等. 差异性视角下自然资源基础调查和专业调查的协同性探讨. 林业建设, 2019, (3): 22-28. [WU H, TANG F L, LIU S J, et al. Study on coordination between natural resource basic and professional survey from the perspective of difference. Forestry Construction, 2019, (3): 22-28.]

[42] 黄贤金. 自然资源统一管理: 新时代、新特征、新趋向. 资源科学, 2019, 41(1): 1-8. [HUANG X J. Unified management of natural resources: A new era, new characteristics, and new trend. Resources Science, 2019, 41(1): 1-8.]

\title{
Research on comprehensive investigation work system of natural resources
}

\author{
GE Liang-sheng, XIA Rui \\ (Comprehensive Survey Command Center for Natural Resources, China Geological Survey, \\ Beijing 100055, China)
}

\begin{abstract}
According to the Chinese president XI Jin- ping's idea of ecological civilization construction in the New Era and the concept of "mountain, river, forest, farmland, lake and grassland are a life community", and in the context of the concept, connotation and attribute analysis of the natural resources, the hierarchical classification scheme of the natural resources serving the comprehensive investigation work, eight basic categories of underground space, minerals, shallow geological layer, land, water, forest, grassland and wetland, and its spacetime and attribute structures were established. Based on these works, the comprehensive investigation system frame of natural resources that follows the basic flow of unified basic investigation, special thematic investigation, dynamic monitoring and data update, data processing and comprehensive integration, results expression and application services, has been primarily built. Besides, the work content and the requirement of each stage have been briefly discussed, which provides a reference for reconstruction of natural resources comprehensive investigation system.
\end{abstract}

Keywords: natural resources; classification; space-time-attribute structure; comprehensive investigation; investigation work system 